\title{
(C) OPEN ACCESS \\ Vaping versus JUULing: how the extraordinary growth and marketing of JUUL transformed the US retail e-cigarette market
}

\author{
Jidong Huang, ${ }^{1}$ Zongshuan Duan, ${ }^{1}$ Julian Kwok ${ }^{1}$ Steven Binns, ${ }^{2}$ Lisa E Vera, ${ }^{2,3}$ \\ Yoonsang Kim, ${ }^{2}$ Glen Szczypka, ${ }^{2}$ Sherry L Emery ${ }^{2}$
}

\begin{abstract}
- Additional material is published online only. To view please visit the journal online (http://dx.doi.org/10.1136/ tobaccocontrol-2018-054382)

${ }^{1}$ School of Public Health, Georgia State University, Atlanta, Georgia, USA ${ }^{2}$ Health Media Collaboratory, NORC at the University of Chicago, Chicago, Illinois, USA

${ }^{3}$ VeraCite Inc, La Jolla,

California, USA
\end{abstract}

\section{Correspondence to}

Dr Jidong Huang, Division of Health Management and Policy, School of Public Health, Georgia State University, Atlanta, GA 30303, USA;

jhuang17@gsu.edu

Received 20 March 2018 Revised 7 May 2018 Accepted 8 May 2018 Published Online First 31 May 2018
Check for updates

To cite: Huang J, Duan Z, Kwok J, et al. Tob Control 2019:28:146-151.

\section{ABSTRACT}

Background While national surveys showed declines in e-cigarette use in the USA between 2015 and 2016, recent reports indicate that JUUL, a sleekly designed e-cigarette that looks like a USB drive, is increasingly being used by youth and young adults. However, the extent of JUUL's growth and its marketing strategy have not been systematically examined.

Methods A variety of data sources were used to examine JUUL retail sales in the USA and its marketing and promotion. Retail store scanner data were used to capture the retail sales of JUUL and other major e-cigarette brands for the period 2011-2017. A list of JUUL-related keywords was used to identify JUULrelated tweets on Twitter; to identify JUUL-related posts, hashtags and accounts on Instagram and to identify JUUL-related videos on YouTube.

Results In the short 3-year period 2015-2017, JUUL has transformed from a little-known brand with minimum sales into the largest retail e-cigarette brand in the USA, lifting sales of the entire e-cigarette category. Its US\$150 million retail sales in the last quarter of 2017 accounted for about $40 \%$ of e-cigarette retail market share. While marketing expenditures for JUUL were moderate, the sales growth of JUUL was accompanied by a variety of innovative, engaging and wide-reaching campaigns on Twitter, Instagram and YouTube, conducted by JUUL and its affiliated marketers.

Conclusions The discrepancies between e-cigarette sales data and the prevalence of e-cigarette use from surveys highlight the challenges in tracking and understanding the use of new and emerging tobacco products. In a rapidly changing media environment, where successful and influential marketing campaigns can be conducted on social media at little cost, marketing expenditures alone may not fully capture the influence, reach and engagement of tobacco marketing.

\section{INTRODUCTION}

Use of electronic cigarettes has increased rapidly over the past decade in the USA, particularly among youth $^{1}{ }^{2-}$ a development that raised significant public health concerns about the creation of a new generation of nicotine dependency. ${ }^{3}$ E-cigarette devices that youth prefer have also evolved substantially over time: from early-generation cigalike e-cigarettes; to more advanced modifiable tank-style e-cigarettes ${ }^{5}$; to the recent emergence of a sophisticated, sleekly designed, discreet high-tech device called JUUL $^{6-}$ a flat, rectangular portable e-cigarette device fashioned to look like a computer flash drive and rechargeable at a USB port. ${ }^{7}$ A JUUL has two basic components: the device, which includes a battery and temperature regulation system, and the prefilled e-liquid cartridge, called a 'JUULpod' which also serves as the mouthpiece. JUUL is manufactured to be a closed system, that is, non-modifiable. ${ }^{6-8}$ JUUL and its competitors, such as Suorin e-cigarettes, are colloquially known as 'pod vaporizers' or 'vape pods.' JUUL is made by the San Francisco-based JUUL Labs, which was founded in early 2017 by two former Stanford graduate students as a spinoff of the Pax Labs, manufacturers of the hybrid Pax brand vaporizers. ${ }^{8}$

Recent news is abuzz with the stories of JUUL's striking appeal to teens and the dramatic increase in JUUL use among the youth population since its mid-2015 market debut. ${ }^{9-14}$ A 2017 survey reported that $8 \%$ of American youth and young adults (aged 15-24 years) used JUUL in the 30 days prior to the survey. ${ }^{15}$ The reported popularity of JUUL among youth has prompted enforcement actions from FDA to stop youth use of, and access to, JUUL and other e-cigarettes. ${ }^{16}$ The characteristics that purportedly make JUUL more popular among youth than its predecessors include its trendy design (called the 'iPhone of e-cigarettes') ${ }^{17}$; youth-friendly flavours like Fruit Medley and Crème Brulee; and JUUL's discreet profile-teens even report having vaped in class. ${ }^{18} 19$ JUUL is reported to contain high levels of nicotine $(0.7 \mathrm{~mL}$ or $59 \mathrm{mg} / \mathrm{mL}$ per pod) and uses a proprietary e-liquid formula (JUULsalts) based on the nicotine salts found in leaf-based tobacco rather than free-based nicotine. ${ }^{20}$ Consequently, JUUL is said to deliver a nicotine peak in about $5 \mathrm{~min}$, and can create an experience more like combustible cigarette smoking than found with other e-cigarettes on the market, ${ }^{21}$ an attribute appealing to both young and adult smokers. ${ }^{7}$

Previous research demonstrated that the rapid growth in e-cigarette use was accompanied by a marked increase in advertising and promotion. $^{22-24}$ Similarly, several news articles have covered JUUL's marketing. ${ }^{725}$ Concerns have been voiced regarding the youth of the men and women portrayed in JUUL's advertising in combination with the product design, which critics believe 'misleads about risk' of addiction. ${ }^{26}$ JUUL is also highly discussed on social media platforms such as Twitter, Instagram, YouTube and Reddit. ${ }^{7} 27$ Because the audiences of these platforms disproportionately represent youth and young adults, ${ }^{28}$ JUUL's marketing and promotion on social media 
may increase the appeal, experimentation, initiation and use of JUUL among that population.

Despite the intense interest in JUUL, studies that document the extent and rate of JUUL's growth, either in absolute sales value or in comparison with other major e-cigarette brands, have been scarce. In addition, research on JUUL marketing, particularly among new media platforms, has been limited. Our study aims to fill these critical gaps in the literature by providing a comprehensive examination of the growth and marketing of JUUL, and their implications for public health policy and research on e-cigarettes and e-cigarette marketing.

\section{METHODS}

\section{Retail store scanner data}

Retail sales data for JUUL and other e-cigarette brands for the period 2011-2017 were obtained from the US retail store scanner data compiled by the Nielsen Company. These data represent quarterly sales of e-cigarettes in Nielsen's participating retailers, which include food, drug and mass stores in 52 US markets and convenience stores in a subset of those markets. For each e-cigarette brand, the Nielsen data include sales of branded devices and branded e-liquid, cartridges, and refills. Nielsen retail sales data do not include e-cigarette sales in non-participating retailers, vape shops and online e-cigarette sales.

\section{Marketing expenditures}

Marketing expenditure data for JUUL were obtained from Kantar Media, which tracks US advertising across media channels including television, print, radio and internet. We used the keywords 'JUUL', 'JUULvapor', 'JUULpod', 'JUULpods' and 'JUUL labs' to query product name, product manufacturer and product category in the Kantar Media Marketing Expenditure database. For product categories that we deemed highly likely to include JUUL products, such as 'smoking materials and accessories,' we manually reviewed each product for relevance. JUUL marketing expenditures data were available from the second quarter of 2015 through the second quarter of 2017. Marketing expenditures were broken down by media channel. Kantar Media marketing expenditures data do not include promotional expenditures to retailers at point-of-sale (POS) and direct promotional expenditures to consumers.

\section{Twitter data}

The number of JUUL-related tweets was obtained from the Twitter Historic Power Track, which provides access to 100\% of all archived tweets, as well as metadata associated with each tweet. Since JUUL was introduced in mid-2015, tweets were collected for the period January 2015 to December 2017. Tweets related to JUUL were identified and collected using a search query rule that specified the tweet or account/profile name containing the text string 'JUUL' regardless of capitalisation or position. Irrelevant tweets, such as those in which JUUL is used as a person's last name, were excluded from our analysis. The English language filter was used in collecting JUUL-related tweets.

\section{Instagram data}

JUUL-related Instagram accounts/profiles were identified from Instagram (www.instagram.com) using a search query rule that specified the account/profile name containing the text string 'JUUL' regardless of capitalisation or position. For each account/ profile, the number of posts, number of followers and number of accounts they follow were recorded and updated through
15 February 2018. In addition, we identified JUUL-related hashtags by using a search query rule that specified the hashtags containing the text string 'JUUL', regardless of capitalisation or position. The total number of posts as of 15 February 2018 using each hashtag was recorded. Due to the large number of hashtags related to JUUL, we only included those hashtags that had at least 500 posts in our analysis. Two coauthors reviewed all the posts published by the official JUUL Instagram account (JUULvapor) and identified eight themes. Two independent coders then coded whether each JUULvapor post fell into one of these eight themes: 'flavour images', 'product images', 'customer feedback/testimony', 'lifestyle appeal images', 'fashion images', 'sponsored events', 'cartoon images' and 'celebrity/model images'. The inter-rater reliability was high (Cohen's $\mathrm{k}=0.91$ ). The discrepancies between the two raters were adjudicated by the two coauthors who identified these themes. In addition, we noted whether the post was a static picture, a GIF picture or a short video. We also recorded the number of likes and comments for each post.

\section{YouTube data}

Top-viewed (\# of views >100000) JUUL-related YouTube videos, as of 1 March 2018, were identified from YouTube ( www.youtube.com) using the keywords 'JUUL', 'JUULing', 'JUULvapor', 'JUULpod', 'JUULpods', 'JUULtips' and 'JUULlabs'. The unique URL, title, number of likes and dislikes, and the post date for each video were recorded. Two coauthors watched all top-viewed videos and identified three major themes-'product review videos', 'product modification videos' and 'lifestyle videos'. Two independent coders then watched each video and double coded the videos into these three themes. The age category of the persons appearing in each video was also recorded. The inter-rater reliability was 0.93 (Cohen's $\mathrm{k}$ ). The discrepancies between the two raters were adjudicated by the senior author. In addition, we recorded the gender and number of people appearing in each video.

\section{RESULTS}

\section{Sales and growth of JUUL}

Figure 1 documents the growth of JUUL retail sales, in comparison with other major e-cigarette brands, in Nielsen-tracked retail stores. E-cigarette retail sales overall have increased significantly since 2011: quarterly e-cigarette retail sales were about US $\$ 19$ million in the first quarter of 2011, which increased to US $\$ 409$ million at the end of 2017. Aggregated annual e-cigarette retail sales increased 16\% between 2015 and 2016 (from US\$775 million to US\$896 million), and increased 47\% between 2016 and 2017 (from US\$896 million to US\$1318 million). Despite dips in a few quarters, the long-term e-cigarette retail sales trend has been on an upward trajectory. This long-term upward trend appears to have accelerated in 2017. There were four key growth periods between 2011 and 2017. The first occurred at the beginning of 2012, with growth driven by a variety of different e-cigarette brands. The second growth period occurred at the beginning of 2013, driven primarily by growth in the Blu and Njoy brands. The third occurred in the third quarter of 2014, driven by growth in Vuse brand; and the last occurred at the second quarter of 2017 , driven exclusively by growth in sales of JUUL.

JUUL has changed the landscape of the e-cigarette retail market in the USA. Because of JUUL's growth, the e-cigarette brands owned by the tobacco industry, which had dominated the e-cigarette retail market since 2013, no longer had the majority 


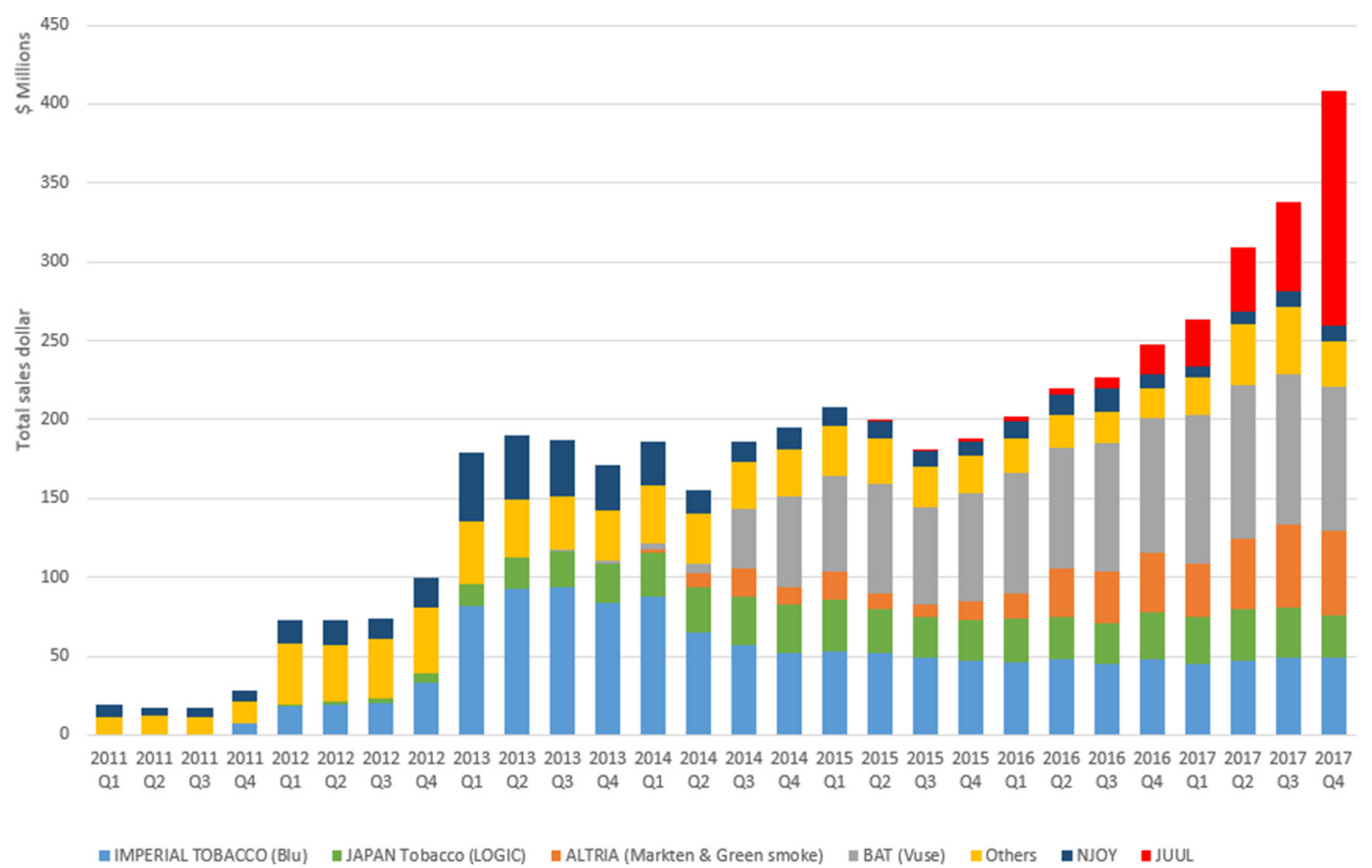

Figure 1 Sales dollar of e-cigarettes in Nielsen-tracked retail channels: by brand 2011-2017.

of the market share at the end of 2017. JUUL's fast growth contrasted dramatically with the e-cigarette brands owned by the tobacco industry, whose retail sales had stagnated since 2015. With quarterly retail sales exceeding US\$100 million and annual retail sales exceeding US\$650 million, JUUL is now the largest e-cigarette brand measured by retail sales, taking up more than half the e-cigarette retail market share. ${ }^{29}$

\section{Marketing expenditures for JUUL}

Marketing expenditures for JUUL from 2015 to 2017 in media channels tracked by Kantar Media are shown in table 1. Kantar recorded US\$2.1 million spent on JUUL marketing between 2015 and 2017. While this figure is significant, it pales in comparison with marketing expenditures for other e-cigarette brands. For example, Vuse spending on television marketing alone in 2015 and 2016 exceeded US\$16 million.

In 2015, Kantar recorded US\$1.6 million spent on marketing by JUUL. The largest spending category was internet display, on which JUUL spent a little over US\$1 million. JUUL also spent slightly more than US\$.5 million on radio advertising in 2015 . The total JUUL marketing expenditures recorded by Kantar decreased substantially from 2015 to 2016, with recorded marketing expenditures in 2016 representing less than one-third those in 2015. While spending on business-to-business (B2B) and outdoor advertising doubled, the drastic decrease in spending on internet display and radio was particularly noticeable. The marked decline in tracked marketing expenditures continued into 2017. In the first half of 2017, JUUL spent no recorded money on major advertising channels tracked by Kantar, and spent only about US\$20K on B2B advertising.

\section{JUUL on twitter}

Figure 2 presents the number of JUUL-related tweets gathered from Twitter between 2015 and 2017. There were scarcely any JUUL-related tweets in 2015 (8416 total captured tweets, with a monthly average of 765). The number of JUUL-related tweets increased substantially in 2016, with a total of 21292 captured tweets and a monthly average of 1774-more than double the number in 2015. The number of JUUL-related tweets exploded in 2017, with the total reaching 366786 and a monthly average of 30565,17 times the 2016 levels. In comparing figure 2 with figure 1, the growth trend in JUUL tweets noticeably tracks well the growth in JUUL retail sales; the two data series were highly correlated, with a correlation coefficient of 0.968 . Importantly, an ordinary least square regression that regressed JUUL quarterly sales on the number of JUUL-related tweets revealed that the number of tweets alone accounted for $93 \%$ of variation in JUUL sales in retail stores. In addition, the official JUUL Twitter account (@JUULvapor) had tweeted more than 4800 posts on Twitter, the vast majority of which were posted since June 2017. The account had more than 12300 Twitter followers as of 28 February 2018.

Table 1 JUUL marketing expenditures in Kantar-tracked channels: 2015-2017

\begin{tabular}{|c|c|c|c|c|c|}
\hline Year & B-to-B DOLS (000) & RADIO DOLS (000) & INT DISPLAY DOLS (000) & OUTDOOR DOLS (000) & $\begin{array}{l}\text { Total \$ } \\
(000)\end{array}$ \\
\hline 2015 (Q3-Q4) & US\$23.3 & US\$538.6 & US\$1034.6 & US\$45.1 & US\$1641.7 \\
\hline 2016 & US\$57.5 & US\$388.8 & US\$0.6 & US\$78.2 & US\$525.1 \\
\hline $2017(\mathrm{Q} 1-\mathrm{Q} 2)^{*}$ & US\$19.6 & US\$ - & US\$ - & US\$ - & US\$19.6 \\
\hline Total & US\$100.4 & US\$927.4 & US\$1035.2 & US\$123.3 & US\$2186.4 \\
\hline
\end{tabular}

${ }^{*}$ Due to the lag in data collection and reporting, the marketing expenditure data for the third and fourth quarters of 2017 were not available at the time of this report. 


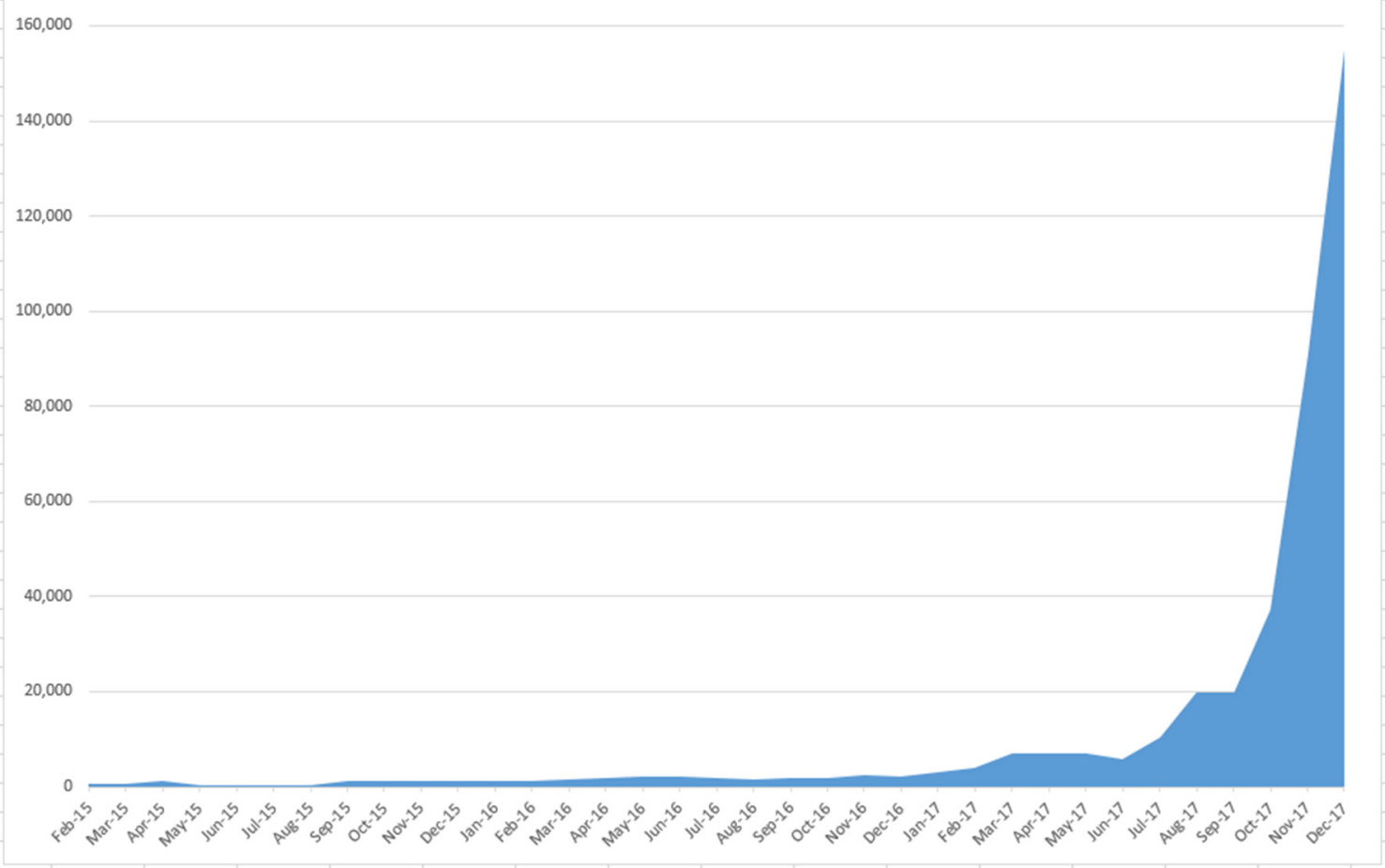

Figure 2 Number of JUUL-related tweets on twitter 2015-2017.

\section{JUUL on Instagram}

We identified seven major JUUL-related Instagram accounts (online supplementary table 1). The official JUUL account on Instagram is JUULvapor, with 129 posts and 32300 followers as of 15 February 2018. The other six JUUL-related accounts were created by online retailers that sell JUUL-related products such as devices, pods, device skins and accessories. The account with the most posts was 'Doit4juul', a social media campaign initiated by online vendor EonSmoke (https://www.eonsmokecom), which called on its followers to share pictures or videos on their own social media accounts that document their experience using JUUL. This campaign has proved highly successful. The 'Doit4juul' account had 81800 followers and was the most-followed JUUL account on Instagram as of 15 February 2018. In addition, as shown below, one of the 'Doit4juul' YouTube videos was one of the most viewed JUUL-related videos on YouTube, with more than 191438 views as of 1 March 2018. One of the Instagram accounts (Juul.girls) specifically targets women and girls. Taken together, these seven JUUL-related accounts had 4230 total posts with over a quarter of a million followers (278 172).

We also identified 14 JUUL-related Instagram hashtags with at least 500 posts and the number of posts associated with each hashtag (online supplementary table 2). Those hashtags include terms that relate to JUUL devices, JUUL pods, JUUL vendors and the term that refers to the act of using JUUL-JUULing. The total number of posts associated with these 14 hashtags was 112 864; however, because one post is usually associated with multiple hashtags, many of these posts may be the same.

A Careful examination of the 129 posts by JUULvapor, the official JUUL Instagram account, revealed (online supplementary table 3 ) that the vast majority of posts (117 of 129) fell into one of four categories: 'lifestyle appeal' (pictures/videos of JUUL that evoke feelings of certain lifestyles such as relaxation, freedom, sex appeal, etc), 'product images', 'customer feedback/testimonies' and 'flavour images'. The 38 posts in the 'product images' category had the most likes among all categories, with 42687 likes. The 'lifestyle appeal' category was the second most popular, with 43 posts and 27352 likes. Taken together, these posts had a total of 7735 comments. An overwhelming majority of posts (123 of 129) were static pictures, rather than GIFs or videos. Most of the posts were posted in 2017 and 2018.

\section{JUUL on YouTube}

Our search query to retrieve JUUL-related videos on YouTube yielded more than 132000 results as of 1 March 2018. However, after two independent coders watched and coded a random sample of 100 videos returned, we found that only 81 of the 100 videos were about JUUL e-cigarettes. This finding indicated that only about $80 \%$ of the 132000 total videos (or about 106000 ) were likely to be related to JUUL e-cigarettes.

As of 1 March 2018, there were 35 YouTube JUUL-related videos that had views over 100000 . We watched and coded the characteristics of all 35 JUUL YouTube videos (online supplementary table 4). In total, these 35 videos had 8297023 views and had garnered 51294 likes and 5808 dislikes. Of the 35, 20 were about 'product reviews', that is, one or more persons in the video were depicted reviewing JUUL or its related products. Interestingly, despite JUUL being a closed system (ie, non-modifiable) e-cigarette, a dozen (12) of the videos were about how to 'modify' the JUUL device (for use of other substance), charger and/or pods (so that they become refillable). One video was about the 'Doit4juul' campaign; one showed a group of surfers chatting about JUUL and one video was a news report. In 23 of these videos, the persons appearing in the video were either youth or young adults. The persons appearing in the videos were predominantly male (28 of 35 ). A vast majority of the videos were posted in 2017 ( 25 of 35 ). One video was posted in 2015, one in 2018 and eight in 2016. 


\section{SUMMARY AND DISCUSSION}

Our study has several key findings with important implications for tobacco use surveillance systems, public policies targeting e-cigarettes and research related to marketing and promotion of new and emerging tobacco products.

First, our analysis shows that aggregated e-cigarette retail sales increased substantially between 2015 and 2017 in the USA, thanks largely to the growth of JUUL. JUUL is now the largest e-cigarette retail brand in the USA, accounting for more than half of the market share in tracked retail channels. JUUL has become so popular that its use has spawned a new verb - JUULing. ${ }^{14}$

Our finding that retail sales of e-cigarettes-and JUUL in particular-increased substantially between 2015 and 2016 contrasts with population prevalence estimates of e-cigarette use from nationally representative surveys. For example, recent CDC reports found that use of e-cigarettes decreased among both US youth and adults between 2015 and 2016 (from 3.5\% to $3.2 \%$ among adults, and from $16.0 \%$ to $11.3 \%$ among youth). ${ }^{130} 31$ While it is possible that those who use e-cigarettes may have increased the amount and frequency of their consumption, this factor alone is unlikely to explain the substantial growth in retail e-cigarette sales during this period. The discrepancy between retail sales data and population prevalence estimates may be due, in part, to the failure of existing surveillance systems to capture use of JUUL and other new and emerging tobacco products. Current tobacco use surveillance systems, which rely heavily on traditional annual nationally representative surveys, are ill-equipped to capture the rapid development of new products. While major tobacco surveys (such as the National Health Interview Survey, the National Adult/Youth Tobacco Survey and the Monitoring the Future survey) have added questions about e-cigarettes since 2014, they ask no specific questions about JUUL and other new/emerging tobacco products. In addition, many teens and young adults who vape do not identify as smokers or e-cigarette users. ${ }^{32}$ Our study highlights the challenges of tracking tobacco use behaviours and tobacco product development in a rapidly changing tobacco market.

Importantly, our study shows that the growth of JUUL was accompanied by innovative marketing across a variety of new media platforms. The marketing of other major retail e-cigarette brands, at least in their early stages, relied heavily on either advertising on TV (eg, Blu and Njoy) ${ }^{33}$ or promotional expenditures to retailers and consumers (eg, Vuse and MarkTen), ${ }^{34}$ or both. However, JUUL was one of the first major retail e-cigarette brands that relied heavily on social media to market and promote its products. In particular, we found the number of JUUL-related tweets was highly correlated with quarterly retail sales of JUUL. In addition to Twitter, JUUL was heavily marketed and promoted on Instagram and YouTube. The official JUUL account on Instagram, for example, used a variety of marketing and promotional schemes to attract, engage with and retain followers. The account used artsy, professional-grade photographs to display its products and evoke lifestyle feelings such as relaxation, freedom and sex appeal. Those posts also heavily emphasised JUUL's variety of flavours. Related accounts heavily marketed and promoted JUUL and associated products including pods, skins and accessories. The seven JUUL-related Instagram accounts identified in this study have amassed over a quarter million followers. Additionally, the number of JUUL-related YouTube videos exceeded 100000 as of 1 March 2018 and engagement with the videos was high. In addition to Twitter, Instagram and YouTube, a recent study found more than 15000 members discussed JUUL-related themes on Reddit. ${ }^{27}$
Our study also found innovative, cross-platform marketing campaigns to promote JUUL such as 'Doit4juul.' Smaller, targeted campaigns such as JUUL.girls also had a large presence across platforms. Our study reveals affiliate marketing 243536 as an important promotional method for JUUL on social media. Such marketing appears as Instagram accounts created by online vendors and product reviews on YouTube. While we cannot verify whether individuals are paid for their JUUL reviews, one young adult reportedly made thousands a month for vaping and reviewing vaping devices on YouTube. ${ }^{25}$

This study has several limitations. First, JUUL retail sales data only capture sales in Nielsen-participating retailers. Those data do not include sales in non-participating retailers or sales occurred online or in vape shops. Therefore, our data underestimated total JUUL sales in the USA. To the extent that online sales may represent a large proportion of total JUUL sales, particularly in its early stage, the growth rate constructed from retail sales may overestimate JUUL's total growth rate. Second, the marketing expenditure data tracked by Kantar do not include POS marketing and promotional expenditures, and the direct promotional expenditures to consumers. For cigarettes, POS promotional expenditures to retailers represented the largest category of marketing expenditures. ${ }^{37}$ This could be true for JUUL as well. As JUUL expanded its presence in retail stores, its marketing expenditure may have shifted from spending on advertising to promotional expenditures at POS. Third, the keywords we used to retrieve JUUL-related content on social media have high precision; however, they may not recall the entire corpus of JUUL-related content. Fourth, while our study provides an overview of marketing and promotion of JUUL on Twitter, Instagram and YouTube, due to limited time and resources, we did not conduct in-depth content analyses of the entire corpus of tweets, posts and videos related to JUUL. Future research can help identify the major themes/topics and sources of JUUL-related content on social media, and identify to what extent JUUL-related discourse on social media was organic versus commercial. In addition, due to the privacy settings and complexity of retrieving data from Facebook, we did not survey JUUL-related content on that platform.

Despite these limitations, our findings have important implications for research and policy. Our analysis suggests that tobacco use surveillance systems should incorporate innovative methods (eg, social media and big data) to capture new and emerging tobacco products in a rapidly evolving market. In addition, our results indicate that marketing expenditures, the conventional measure of marketing influence, may no longer fully capture the extent, reach and influence of marketing and promotion for new and emerging tobacco products. The decrease in marketing expenditures for JUUL over time masks its highly successful, influential, engaging, wide-reaching campaigns on social media.

\section{What this paper adds}

- Recent nationally representative surveys indicate declines in e-cigarette use between 2015 and 2016 in the USA. However, these surveys may have failed to capture the use of a relatively new product, JUUL.

- We systematically document the extent and rate of growth in JUUL retail sales and market share since the product's debut in mid-2015.

- We also examine JUUL's marketing strategies, influence and reach on a variety of social media platforms. 
In fact, our analyses show that JUUL's social media activities were highly correlated with JUUL retail sales. Targeted cross-platform social media campaigns, although they cost little, can have substantial influence on people's attitudes, beliefs and behaviours related to these products.

Contributors JH and SLE designed the study. JH, ZD, JK, SB, LEV, YK and GS collected data and conducted data analysis. JH wrote the first draft; the final version of this paper has been reviewed and approved by all coauthors.

Funding The study is supported, in part, by an NIH-funded grant (R01CA194681, PI Jidong Huang).

Disclaimer The funding agencies played no role in study design, in the collection, analysis and interpretation of data, in the writing of the report and in the decision to submit the article for publication. The content in this paper is solely the responsibility of the authors and does not necessarily represent the official views of the sponsors.

Competing interests None declared.

Patient consent Not required.

Provenance and peer review Not commissioned; externally peer reviewed.

Open access This is an open access article distributed in accordance with the Creative Commons Attribution Non Commercial (CC BY-NC 4.0) license, which permits others to distribute, remix, adapt, build upon this work non-commercially, and license their derivative works on different terms, provided the original work is properly cited and the use is non-commercial. See: http://creativecommons.org/ licenses/by-nc/4.0/

(c) Article author(s) (or their employer(s) unless otherwise stated in the text of the article) 2019. All rights reserved. No commercial use is permitted unless otherwise expressly granted.

\section{REFERENCES}

1 Jamal A, Gentzke A, Hu SS, et al. Tobacco use among middle and high school students - United States, 2011-2016. MMWR Morb Mortal Wkly Rep 2017;66:597-603.

2 US Department of Health \& Human Services. E-cigarette use among youth and young adults: a report of the surgeon general. Atlanta, GA: US Department of Health and Human Services, Centers for Disease Control and Prevention, National Center for Chronic Disease Prevention and Health Promotion, Office on Smoking and Health, 2016.

3 Grana RA. Electronic cigarettes: a new nicotine gateway? J Adolesc Health 2013;52:135-6

4 Legacy Foundation for Health. Vaporized: E-cigarettes, advertising, and youth. Washington, DC: Legacy Foundation for Health, 2014. (accessed 14 Mar 2018).

5 Barrington-Trimis JL, Gibson LA, Halpern-Felsher B, et al. Type of E-Cigarette device used among adolescents and young adults: findings from a pooled analysis of eight studies of 2166 vapers. Nicotine Tob Res 2018;20:271-4.

6 Truth Initiative. What is JUUL? Washington, DC: Truth Initiative, 2018. (accessed 14 Mar 2018).

7 Kee C. Everything you need to know about the JUUL, including the health effects: Buzzfeed News, 2018. (accessed 14 Mar 2018).

8 Bellafante G. Cool-looking and sweet, Juul is a vice teens can't resist: N. Y. Times, 2018. (accessed 14 Mar 2018).

9 Beal K. JUUL e-cigarettes make their way into local schools. 2018 http://wset.com/ news/local/juul-e-cigarettes-make-their-way-into-local-schools (accessed 14 Mar 2018).

10 Coughlin S. We asked teens to explain Juuling to us \& Wow Refinery. 2018. http:// www.refinery29.com/2018/02/190089/what-is-juul-e-cigarette-vaping-teenagers (accessed 14 Mar 2018).

11 Grigorian G. Juuling at Dartmouth: Addiction renewed and reimagined. The Dartmouth 2018. http://www.thedartmouth.com/article/2018/02/juuling-atdartmouth-addiction-renewed-and-reimagined (accessed 14 Mar 2018).
12 Saggio J. What is a Juul? It's a trend parents need to know about Fla. Today. 2018. https://www.floridatoday.com/story/news/2018/02/02/what-juul-its-trend-parentsneed-know/1070088001/ (accessed 14 Mar 2018).

13 Suiters K. Are your kids JUULing at school? 7 on your side investigates. Abc 7wila 2018. http://wjla.com/features/7-on-your-side/are-your-kids-juuling-at-school-7-onyour-side-investigates (accessed 14 Mar 2018).

14 Teitell B. "Juuling": The most widespread phenomenon you've never heard of. Boston Globe 2017. https://www.bostonglobe.com/metro/2017/11/15/where-teenagers-arehigh-school-bathrooms-vaping/JJ6XYWWIOTKqsUGTTIw4U0/story.html (accessed 14 Mar 2018).

15 Willett JG, Bennett M, Hair EC, et al. Recognition, use and perceptions of JUUL among youth and young adults. Tob Control 2018:tobaccocontrol-2018-054273.

16 FDA. Press Announcements - Statement from FDA Commissioner Scott Gottlieb, M.D., on new enforcement actions and a Youth Tobacco Prevention Plan to stop youth use of, and access to, JUUL and other e-cigarettes. https://www.fda.gov/NewsEvents/ Newsroom/PressAnnouncements/ucm605432.htm (accessed 30 Apr 2018).

17 Radding B. Pax Juul: the iPhone of e-cigs? Mens Fit 2015 https://www.mensfitness. com/life/gearandtech/pax-juul-iphone-e-cigs (accessed 14 Mar 2018).

18 Bertholdo S. Vaping goes mainstream: High tech devices especially popular on local campuses. The Acorn 2018. https://www.theacorn.com/articles/vaping-goesmainstream/ (accessed 14 Mar 2018).

19 Chen A. Teenagers embrace JUUL, saying it's discreet enough to vape in class: Natl. Public Radio, 2017. (accessed 14 Mar 2018).

20 JUUL. Manufacturing quality: what is JUUL? San Francisco, CA: JUUL Labs, Inc. https:// support.juulvapor.com/home/learn/faqs/manufacturing-quality\#materials. (accessed 14 Mar 2018).

21 Lawler R. Vaporization startup Pax Labs introduces Juul, its next-gen e-cigarette. Techcrunch.com 2015. https://techcrunch.com/2015/04/21/pax-juul/ (accessed 14 Mar 2018).

22 Kornfield R, Huang J, Vera L, et al. Rapidly increasing promotional expenditures for e-cigarettes. Tob Control 2015;24:110-1.

23 Huang J, Kornfield R, Emery SL. 100 Million views of electronic cigarette youtube videos and counting: quantification, content evaluation, and engagement levels of videos. J Med Internet Res 2016;18:e67.

24 Huang J, Kornfield R, Szczypka G, et al. A cross-sectional examination of marketing of electronic cigarettes on Twitter. Tob Control 2014;23:iii26-30.

25 Conti A. This 21 -year-old is making thousands a month vaping on YouTube.Vice. com. 2018. https://www.vice.com/en_ca/article/8xvjmk/this-21-year-old-is-makingthousands-a-month-vaping-on-youtube (accessed 14 Mar 2018).

26 Harty D. JUUL hopes to reinvent e-cigarette ads with "Vaporized" campaign Ad Age. 2015. http://adage.com/article/cmo-strategy/juul-hopes-reinvent-e-cigarette-adscampaign/299142/ (accessed 14 Mar 2018).

27 Kavuluru R, Han S, Hahn EJ. On the popularity of the USB flash drive-shaped electronic cigarette Juul. Tob Control 2018:tobaccocontrol-2018-054259.

28 Pew Research Center. Social media use in 2018. 2018. http://assets.pewresearch. org/wp-content/uploads/sites/14/2018/03/01105133/PI_2018.03.01_Social-Media_ FINAL.pdf (accessed 25 Apr 2018).

29 Herzog B, Kanada P. Nielsen: tobacco "all channel" data april 21 2018. 2018.

30 Phillips E, Wang TW, Husten CG, et al. Tobacco product use among adults - United States, 2015. MMWR Morb Mortal Wkly Rep 2017;66:1209-15.

31 CDC. QuickStats: percentage* of adults who ever used an E-cigarette ${ }^{\dagger}$ and percentage who currently use E-cigarettes, ${ }^{\S}$ by age group - National Health Interview Survey, United States, 2016". MMWR Morb Mortal Wkly Rep 2017;66:892.

32 Agaku I, Odani S, Vardavas C, et al. Self-Identified tobacco use and harm perceptions among US Youth. Pediatrics 2018;141:e20173523.

33 Duke JC, Lee YO, Kim AE, et al. Exposure to electronic cigarette television advertisements among youth and young adults. Pediatrics 2014;134:e29-36.

34 Herzog B, Gerberi J, Scott A. A vaping state of mind - e-cig/vapor fireside chats. New York, N.Y: Wells Fargo Securities, LLC, 2014.

35 Grana RA, Glantz SA, Ling PM. Electronic nicotine delivery systems in the hands of Hollywood. Tob Control 2011;20:425-6.

36 Grana R, Benowitz N, Glantz SA. E-cigarettes: a scientific review. Circulation 2014;129:1972-86.

37 U.S. Federal Trade Commission.. Federal trade commission cigarette report for 2016 2018. https://www.ftc.gov/reports/federal-trade-commission-cigarette-report-2016federal-trade-commission-smokeless-tobacco (accessed 25 Apr 2018). 